\title{
Contribuições do Núcleo de Estudos em Psicanálise e Educação: a articulação psicanálise e educação e o significado de aluno-sujeito
}

\section{Some contributions from the Núcleo de Estudos em Psicanálise e Educação: the psychoanalysis and education articulation and the meaning of student-subject}

\author{
Tamara da Silveira Valente ${ }^{1}$
}

\begin{abstract}
RESUMO
Neste artigo são apresentados os objetivos do Núcleo de Estudos em Psicanálise e Educação, do Setor de Educação, da Universidade Federal do Paraná (UFPR), criado em 2008. Foi dado ênfase a alguns aspectos de pesquisas efetivadas no Programa de Pós-Graduação em Educação do Setor de Educação da UFPR, notadamente àqueles relacionados às possíveis contribuições da psicanálise ao ato educativo, e ao conceito de sujeito. As reflexões conduziram à noção de que a Psicanálise pode contribuir com Educação, entre outros motivos porque professores e educadores que conhecem os conceitos da metapsicologia se permitem construir com eles uma nova concepção de educação e consequentes inovações em seu ato educativo.
\end{abstract}

Palavras-chave: psicanálise e educação; aluno-sujeito; ato educativo; pesquisa.

\footnotetext{
ABSTRACT

This essay presents the objectives of the Núcleo de Estudos em Psicanálise e Educação, from the Education Sector of the Federal University of Paraná

DOI: $10.1590 / 0104-4060.49810$

1 Universidade Federal do Paraná. Setor de Educação. Curitiba, Paraná, Brasil. Rua General Carneiro, nº 460. Centro. CEP: 80060-150.E-mail: tamara@ufpr.br
} 
(UFPR), created in 2008. Emphases were given to some aspects of researches conducted in the Post Graduate Studies Program in Education, of the UFPR Education Sector, notably those related to the possible contributions of the psychoanalysis theoretical frame to the educational act, as well as, to the concept of subject. The results led to the notion that Psychoanalysis can contribute with Education, among other reasons, because teachers and educators once counting with the metapsychological concepts can allow themselves to build a new conception of education, producing consequent innovations in their educational act.

Keywords: psychoanalysis and education; student-subject; educational act; research.

\section{Introdução}

O Núcleo de Estudos em Psicanálise e Educação (NEPE), do Setor de Educação da Universidade Federal do Paraná, foi criado em 2008 com a proposta de trazer as contribuições desenvolvidas no campo da psicanálise para a educação, com a intenção de que o produto das discussões chegasse à comunidade interna e externa da universidade em forma de reflexões teóricas que pudessem provocar ações educativas novas que servissem às escolas de educação infantil, ensino fundamental e ensino médio.

Estando situado dentro do Setor de Educação de uma universidade, buscava-se, de um modo mais preciso, responder à questão que se colocava então de o escopo teórico da psicanálise poder contribuir com reflexões afetas à educação, tomada na sua acepção mais abrangente. Ao mesmo tempo, naquele momento, se impunha uma discussão mais aprofundada sobre a inclusão escolar de crianças com autismo ou psicose, uma vez que era desconhecido dos alunos de Pedagogia à época, a concepção de autismo e psicose infantil para a teoria da psicanálise ou metapsicologia.

Para situar a discussão que segue se torna necessário conceituar o termo metapsicologia. Freud empregou o termo metapsicologia pela primeira vez na carta 41, enviada a Fliess, datada de 13 de fevereiro. (GARCIA-ROZA, 2008, p. 9, ROUDINESCO; PLON, 1998, p. 511). Na nota de rodapé 1 , relativa à Carta 84, Strachey (1977, p. 370, nota de rodapé) informa que o conceito foi publicado pela primeira vez no capítulo XII C de A Psicopatologia da Vida Cotidiana (1901b) e, depois, no artigo sobre O Inconsciente (1915e), tendo o seu uso se tornado cada vez mais frequente, sem que Freud tenha dado uma explicação definitiva para o que chamou de metapsicologia. 
Ao lermos o verbete sobre metapsicologia no Dicionário de Psicanálise de Roudinesco e Plon (1988, p. 511) fica a impressão de que Freud tentava com tal termo distinguir o seu pensamento a respeito do processo psíquico do que propunham a biologia e a psicologia contemporâneas. Garcia-Roza (2008, p. 11) sugere que, no sentido mais amplo, o termo metapsicologia designa o conjunto da elaboração teórica de Freud, com o que concordam Laplanche e Pontalis (1983), para quem "o termo foi criado por Freud para designar a psicologia por ele fundada, considerada na sua dimensão mais teórica" (LAPLANCHE; PONTALIS, 1983, p. 361) e, também, Roudinesco e Plon (1998), que afirmam que "a abordagem metapsicológica consiste na elaboração de modelos teóricos que não estão diretamente ligados a uma experiência prática ou a uma observação clínica [...]”. (ROUDINESCO; PLON, 1998, p. 511).

Partindo da ideia de que a psicanálise é um campo de conhecimento que tem como objeto próprio de estudos os processos inconscientes e que, tradicionalmente, o conhecimento produzido pela psicanálise tem se voltado para a prática clínica, lançou-se a hipótese de que ele pudesse contribuir com outros campos, especificamente, neste caso, com a educação. A hipótese então era a de que a educação pode se beneficiar dos fundamentos epistemológicos desse saber que fornece uma explicação de como se constitui o sujeito do inconsciente, e de conhecer como os conceitos daí derivados impactam nos processos educacionais, também tomados aqui na sua acepção mais ampla.

De fato, no pensamento de Kupfer (2001), a psicanálise, entendida não só como um corpo teórico tecido nos finais do século XIX e início do século $\mathrm{XX}$, mas também como resultante de cem anos de práticas, análises, movimentos institucionais, pôs-se a dialogar com a educação nas escolas, na mídia, na universidade, produzindo mudanças. (KUPFER, 2001, p. 117-8). Tomando a educação como discurso social, e dialogando com ela dentro do campo social, a psicanálise também mudou e "deixou de ser uma prática do divã, e hoje ganhou a as instituições, os hospitais - e as escolas". (KUPFER, 2001, p. 118).

Ao discutir os alcances e limites da psicanálise para a educação, Almeida (2006) sugere ser essa uma questão ética complexa, que comporta estabelecer uma distinção entre a transmissão da psicanálise em intensão e a transmissão da psicanálise em extensão. A primeira estaria vinculada à formação do analista, resguardando-se para ela o termo "transmissão", e a segunda estaria afeta à formação de educadores e outros profissionais do campo da cultura e das instituições sociais, sob os termos ensino, divulgação ou difusão (ALMEIDA, 2006 , p. 18, grifos da autora). 
Assim concebidos, o estudo da teoria, sua aplicação na clínica, sua articulação com outro saberes e produções culturais [...] e com algumas práticas sociais como a educação, por exemplo - seriam objeto de ensino e de difusão, [...]. (ALMEIDA, 2006, p. 18-9, grifos da autora).

Assim, dentro do escopo do NEPE, foram elaborados alguns objetivos, dentre os quais constava promover reflexões acerca dos conceitos psicanalíticos, desenvolver pesquisas que conjugassem os conceitos psicanalíticos e os pedagógicos visando à construção de novos elementos teóricos que contribuíssem para as reflexões sobre o ato educativo, e, propor atividades de extensão voltadas para a comunidade interna e externa à universidade, eventos em que seriam divulgados os resultados das pesquisas realizadas pelas alunas nas modalidades de mestrado, iniciação científica e trabalho de conclusão de curso.

Iniciados os trabalhos, foi estabelecido um eixo de interesse ligado à docência, à pesquisa e à extensão, dividido em duas vertentes: os processos inconscientes e sua implicação na aprendizagem e na relação professor-aluno, e a inclusão escolar de crianças autistas e psicóticas. No campo da docência, a primeira vertente foi assistida pela disciplina optativa Psicanálise e Educação, tendo como ementa conhecer os "Aspectos teóricos básicos da Psicanálise. Processos inconscientes e sua implicação na aprendizagem e na relação professor-aluno", com a qual se pretende que o aluno conheça os conceitos teóricos básicos do saber psicanalítico e os limites e as possibilidades de uma perspectiva teórica que leva em consideração os processos inconscientes implicados no ato educativo. (VALENTE, 2008).

$\mathrm{Na}$ segunda vertente, a disciplina de apoio foi Tópicos Especiais em Psicologia da Educação, que é uma disciplina em que os professores discutem assuntos referentes ao que pesquisam, e cuja ementa é estudar "A relação entre Psicologia da Educação, Educação e mundo contemporâneo. Discussão das propostas de pesquisa e/ou intervenção relativas a problemas atuais no contexto educacional", tendo como subtítulo, nesse caso, "Contribuições da Articulação Psicanálise e Educação para a inclusão escolar de alunos autistas e psicóticos", com a qual pretende-se que, ao final do curso, o aluno conheça alguns conceitos propostos pela articulação psicanálise e educação relativos à inclusão escolar de alunos autistas e psicóticos. (VALENTE, 2008).

No que diz respeito à pesquisa, e sempre com aquela indagação inicial relativa a se o corpo conceitual da psicanálise poderia realmente ser um coadjuvante do ato educativo, surgiram outras questões emergidas do desejo de saber das alunas-pesquisadoras que se dedicaram ao estudo de diferentes conceitos oriundos da psicanálise, dos quais se destaca a busca de compreensão do que 
seja o aluno-sujeito, ou dizendo de outro modo, o sujeito no aluno. Assim, serão abordadas a seguir algumas pesquisas realizadas no âmbito do programa de Pós-graduação em Educação do Setor de Educação da Universidade Federal do Paraná que trataram desses temas.

\section{O sujeito no aluno nas pesquisas do NEPE}

Nesse sentido, temos os trabalhos de Salgado (2012), pedagoga e professora, que se dedicou a investigar as percepções dos professores da escola pública sobre a inclusão escolar de crianças autistas e psicóticas no ensino regular; a de Pucovski (2013), pedagoga, que se debruçou sobre a inclusão escolar de alunos autistas já inseridos em instituições escolares, sendo que, mais especificamente, a ela interessou conhecer as falas e ações do professor desse aluno que, no seu processo de ensino, indicasse concebê-lo como aluno sujeito. E, ainda, o trabalho de Fernandes (2013), psicanalista, que, preocupada com a relação que o professor estabelece com seu aluno psicótico em processo de inclusão na escola regular de ensino, dedicou-se a estudar aspectos dessa relação circunscritos às atividades em sala de aula; e também o de Lopes (2014), pedagoga e professora, que apresentou uma discussão sobre alguns conceitos elaborados pela psicanálise, notadamente o de aluno-sujeito, que ela entende como operadores teóricos que podem auxiliar os professores no seu ato educativo cotidiano.

Em seu estudo, Salgado (2012), a partir das falas e das reflexões que professores fazem da sua prática cotidiana com alunos autistas e psicóticos, passou a conhecer os obstáculos, mas, também, a possível superação desses obstáculos. Para ela, perante a tarefa de educar uma criança autista ou psicótica, a psicanálise contribui com rigor quando sugere que o professor se implique

[...] em revisar concepções, principalmente já que estar na posição de mestre exige do professor equilíbrio e uma postura ética na condução do seu ato educativo, a fim de que possa renunciar ao saber-todo e se lançar no exercício de ser um mestre não-todo. (SALGADO, 2012, p. 131 , grifos da autora).

Ser um Mestre-não-todo para Almeida (2006) significa em primeiro lugar que o analista nessa posição transmite ao educador a ideia da castração, fonte da 
concepção de que nem tudo é possível diante do ato educativo, de que a falta-a-ser é condição para a emergência do desejo, desejo esse que nos determina enquanto seres humanos. Também, a noção de que o Mestre-não-todo provê ao educador modos de ele se perceber submetido à Lei, legitimando o Nome do Pai e a função paterna, restaurando para si os limites de seu ato educativo. E, ainda, que o Mestre-não-todo é aquele que

ao encarnar o impossivel da educação como ideal pedagógico a ser atingido, apontando para o real da falta que atravessa todo e qualquer (trans)missão educativa, o analista poderá vir a transcender seu ensino e transformá-lo em transmissão de um estilo. (ALMEIDA, 2006, p. 21, grifos da autora).

Mais especificamente em relação ao conceito de aluno-sujeito, ou, o sujeito no aluno, as autoras dos trabalhos mencionados acima mostram que é fator favorável à inclusão ou aos processos de aprendizagem de alunos autistas ou psicóticos os professores fazerem refletir o significado desse construto teórico em seu ato educativo. Salgado (2012) termina seu estudo acreditando que os professores participantes da sua pesquisa, por implicarem-se subjetivamente com o seu ato educativo, demonstraram possibilidades no sentido de trabalhar em prol da inclusão de seus alunos autistas ou psicótico mediante a visada de uma educação que leva em conta o sujeito, dando chances para que ambos atuem em nome próprio, professor e aluno, crença essa nascida de seu esforço em conhecer os pressupostos teóricos da psicanálise. (SALGADO, 2012, p. 137).

Pucovski (2013), por sua vez, na conclusão do seu estudo considerou que os professores que participaram de sua pesquisa enxergam o seu trabalho pelo viés da possibilidade ao adotarem a posição de considerar as particularidades de seu aluno em seu ato educativo, "em que no processo de ensino, estão considerando o sujeito, em seu aluno" (PUCOVSKI, 2013, p. 101), contribuindo para o engendramento de uma nova visão de educação escolar inclusiva.

Com relação às falas e às ações do professor de alunos com psicose, Fernandes (2013) observou que a relação que o professor estabelece com seu aluno depende de como ele vê esse aluno; "se ele o vir sob o prisma do déficit, as suas falas e ações trilharão a via da impossibilidade", mas, se ele "pressupuser um sujeito em seu aluno psicótico, ele vai demandar dele as mesmas coisas que demanda de um aluno que não seja de inclusão" (FERNANDES, 2013, p. 96), sempre tendo em mente que ele não vai responder do mesmo modo, devido à sua constituição psicótica. Assim, essa autora considera que a noção de sujeito 
como propõe a psicanálise, que amarra o que é do saber ao que é do desejo, instituindo aí uma diferença, contribui para as reflexões do professor que passa a ter uma base teórica que sustenta a existência da particularidade em cada aluno, de inclusão ou não. (FERNANDES, 2013, p. 97-8).

Das leituras que empreendeu das dissertações e teses que vinculam a psicanálise à educação, Lopes (2014) depreendeu que predomina nesses estudos a ideia de uma filiação à perspectiva da (psico)pedagogia de cunho tecnicista, conceito formulado por Lajonquière, para mostrar o equívoco que esse saber produz na formação de professores, e, em nenhuma delas foi abordado o conceito de sujeito como propõe a Articulação Psicanálise e Educação, cuja base é o sujeito do inconsciente. Ao falar desse sujeito, Lopes (2014) concorda com Lajonquière, que propõe o ato educativo como aquele que contribui para o aluno criar recursos psíquicos próprios "que propiciem em si a emergência do sujeito, de um sujeito caracterizado por suas diferenças, por sua singularidade subjetiva". (LOPES, 2014, p. 73). Ela menciona também a posição de Kupfer (2001) para quem, ao reconhecer que o aluno está constituído por um inconsciente, ao qual ele não tem acesso, "o professor não pode esperar que saiba, daquilo que está oferecendo ao seu aluno, o que se transformará em aprendizagem”. (LOPES, 2014, p. 47). E, por isso, o professor contribui oferecendo ao seu aluno os objetos de seu saber, para que deles o aluno tome o que fizer sentido para si. (KUPFER, 2001, p. 125).

Mas, afinal, em que consiste esse conceito de sujeito como propõe a Articulação Psicanálise e Educação?

Segundo Vieira (2010, p. 91), Freud não explorou muito a noção de sujeito em toda a sua obra, exceto no artigo As pulsões e suas vicissitudes (1915). "Foi Jacques Lacan, entre 1950 e 1965, quem elaborou a noção lógica e filosófica do sujeito no âmbito de sua teoria do significante, transformando o sujeito da consciência num sujeito do inconsciente, da ciência e do desejo". (ROUDINESCO; PLON, 1988, p. 742). Termo central da teoria proposta por Lacan "o significante transformou-se em psicanálise, no elemento significativo do discurso (consciente ou inconsciente) que determina os atos, as palavras e o destino do sujeito, à sua revelia e à maneira de uma nomeação simbólica. (ROUDINESCO; PLON, 1988, p. 708).

Torezan e Aguiar (2011, p. 529) lembram que a psicanálise surgiu num momento em que o discurso teológico é substituído pelo discurso da ciência, e passa a prevalecer a noção de subjetividade dada pela razão, ficando aquela submetida à consciência, na qual impera o eu, reduzindo "o conceito de inconsciente a um estado de caráter temporário e adjetivado, uma espécie de adendo desconhecido da consciência". (TOREZAN; AGUIAR, 2011, p. 530). No entanto, Freud, ao introduzir o conceito de inconsciente como estrutura 
determinante da subjetividade, produz um abalo nessa concepção e inaugura o conceito de sujeito cindido em dois modos de funcionamento, instituindo o sujeito do consciente e o sujeito do inconsciente.

Esses autores destacam que, ao contrário do que se supõe, o modo de operar característico do inconsciente não é arbitrário, ou caótico, ou ilógico, apenas que a lógica do inconsciente nas "formações do inconsciente - sonhos, chistes, lapsos, atos falhos, apontados na teoria freudiana como formas metafóricas de manifestação do inconsciente - indicam, mais uma vez, a existência de um sujeito não unificado". (TOREZAN; AGUIAR, 2011, p. 531-532). Formas metafóricas diz respeito a um modo de linguagem em que "a significação natural de uma palavra é substituída por outra, em virtude de relação de semelhança subentendida". (FERREIRA, 1975, p. 917).

Torezan e Aguiar (2011, p. 531) acreditam que a proposta de Freud sobre o inconsciente é caracterizá-lo como uma instância psíquica marcada por uma particular maneira de operar, regulada por leis diferentes daquelas ordenadoras da consciência.

Para Kupfer (2001, p. 121), atualmente, a psicanálise é o corpo de conhecimento que faz o resgate do conceito de sujeito. A principal dificuldade na apreensão dessa noção, também apontada por Torezan e Aguiar (2011, p. 529), está na confusão que se faz entre a noção cartesiana de sujeito - agente de seu próprio discurso e centrado em seu eu - e a posição freudiana e lacaniana de sujeito - efeito de discurso, descentrado, marcado pela falta.

Este sujeito não coincide com o sujeito do cogito da filosofia cartesiana, tampouco com o sujeito-organismo de Piaget. Para a psicanálise, o sujeito do inconsciente se constitui na e pela linguagem. Desta perspectiva, a linguagem é [...] a trama mesma de que é feito o sujeito. Tal formação aparece de modo evanescente, nos interstícios das palavras, como produto do encontro entre eles. (KUPFER, 2001, p. 124).

Kupfer (2001) estabelece uma diferença entre a criança e o sujeito na criança. A criança, para ela, se desenvolve, e esse desenvolvimento está afeto à esfera do organismo biológico. O sujeito, por sua vez, se constitui pari passu à sua estruturação psíquica. O sujeito vai se constituindo na dependência de que o Outro atue falando à criança desde seu nascimento, dando causa ao sujeito por meio de inscrições primordiais, simbolização essa que vai lhe fornecer os recursos de linguagem que vão lhe prover modos de direção de seu percurso pelo mundo. Esse Outro "[...] desejante da criança, engendrou-a e adotou-a 
para que ocupe um lugar em sua cadeia significante. Um lugar no conjunto de significações que determinam, que têm importância para esse outro desejante da criança”. (KUPFER, 2001, p. 124-125).

Assim, para Kupfer (2011, p. 125), um educador que opera visando ao sujeito fala ao aluno apresentando os objetos do mundo, que nada mais são senão os conteúdos que ensina, dos quais o aluno tomará para si aqueles com os quais faça laço. Pois, conforme coloca Lajonquière (2009)

\begin{abstract}
Em toda educação está em questão a transmissão de um conjunto parcial de conhecimento ou uma amostra daquilo que os outros souberam acumular com antecedência. Porém, aquele que aprende algo não só adquire um certo domínio sobre algum dos mundos possíveis - aqueles das letras, da natureza, ou das virtudes humanas, dentre outros - mas também, é marcado pelo apre(e)ndido no próprio coração da vida. (LAJONQUIÈRE, 2009, p. 167).
\end{abstract}

Apostando na distinção entre criança e sujeito, Lajonquière (2009) considera que o educador que se coloca na posição de educar o sujeito, fala à criança. Mas, uma fala na qual o aluno, por deslocamento e condensação na tessitura de seu pensamento, seja convocado a se perguntar o que quer seu professor quando lhe fala. "Essa pergunta sem resposta conclusiva indica o desejo em causa no ato educativo, um ato de fala no interior do campo da palavra e da linguagem capaz de enlaçar um devir adulto". (LAJONQUIÈRE, 2009, p. 173).

\title{
A metapsicologia nas pesquisas do NEPE
}

No que diz respeito a se o corpo conceitual da psicanálise, ou metapsicologia, pode realmente ser um coadjuvante do ato educativo, provendo aos educadores subsídios teóricos que possam auxiliá-los a formar uma nova concepção de aluno autista ou psicótico e a propor consequentes novos modos de atuar em seu ato educativo, passa-se a abordar as contribuições dos estudos de Salgado (2012), Pucovski (2013), Fernandes (2012) e Lopes (2014), já mencionadas, às quais serão acrescidas as pesquisas de Fleith (2012) e de Cotarelli (2014), também promovidas no âmbito do NEPE.

Salgado (2012, p. 131) acredita que a psicanálise contribui com rigor quando sugere ao professor que, diante da tarefa de educar seu aluno autista ou 
psicótico, conduza o seu ato educativo levando em conta não só o sujeito em seu aluno, mas também se reconheça como um sujeito barrado, castrado, pela própria impossibilidade da sua profissão. Ela lembra também que pensar a formação de professores para atuar na inclusão escolar de crianças autistas e psicóticas é mais do que proporcionar informações de cunho didático-metodológicas, pois implica em revisar concepções e adotar uma nova posição diante do seu ato de educar.

O estudo empreendido por Pucovski (2013, p. 9), que também se colocou na posição investigativa de conhecer se e como o referencial teórico formulado pela articulação psicanálise e educação poderia contribuir para a discussão sobre a relação que o professor estabelece com seu aluno autista, levou-a a concluir que as possibilidades de inclusão são grandemente favorecidas se se produzir entre eles um "laço educativo". "Se o professor estiver atravessado pelo saber psicanalítico, poderá conhecer as vicissitudes do processo de subjetivação de seu aluno autista [...], basta o professor implicar-se com seu aluno para que o ato educativo surta o efeito de produzir marcas 'subjetivantes"'. (PUCOVSKI, 2013, p. 102).

Fernandes (2013, p. 97-8) acredita que a interlocução psicanálise-educação, ou, dito de outro modo, a Articulação Psicanálise e Educação, pode contribuir para a discussão sobre a relação que o professor estabelece com seu aluno com psicose. Além do conceito de sujeito, proposto pela psicanálise, ela adota esse suporte teórico para apresentar o conceito de psicose. Tendo como um dos objetivos da sua pesquisa circunscrever esse conceito, Fernandes (2013) buscou o conceito lacaniano de Nome do Pai. Esse significante estabelece a condição para que o psiquismo de uma criança, no início da sua constituição, separe-se do outro primordial (a mãe ou função materna) e se lance no campo do desejo, campo fundamental para a relação que esse sujeito vai estabelecer com o mundo, e também com o saber. Ocorre que na psicose há a foraclusão do significante Nome do Pai, e o psiquismo da criança que não realizou a separação mantém-se ligado ao desejo materno, produzindo impasses na sua constituição. (FERNANDES, 2013, p. 97).

Lopes (2014), por sua vez, em sua pesquisa, tece algumas críticas à Pedagogia Científica a partir das posições teóricas de alguns teóricos da psicanálise, tais como Mrech (2003), Japiassu (2009) e Lajonquière (1999; 2010), ilustradas pelo resultado de algumas dissertações e teses realizadas em programas de pós-graduação de algumas universidades brasileiras. Ela ressalta que é, sobretudo, na discussão sobre alguns conceitos elaborados pela psicanálise, notadamente o de sujeito, que vê a possibilidade de esse referencial teórico auxiliar os professores no seu ato educativo cotidiano. (LOPES, 2014, p. 71-3).

Com objetivos diferentes dos estudos acima expostos, mas também buscando conhecer se a metapsicologia poderia contribuir para a educação, foram 
desenvolvidas no âmbito do NEPE as dissertações elaboradas por Fleith (2012) e por Cotarelli (2014).

Fleith (2012), psicanalista, ocupou-se em seu estudo de questões relativas aos modos de simbolização da criança autista ou psicótica e "das suas possibilidades de fazer laço com os demais e de representar e significar a experiência". (FLEITH, 2012, p. 10). Ela estabeleceu como objetivo geral de seu estudo buscar conceitos dentro do referencial psicanalítico que lançassem luz à compreensão dos processos de pensamento e linguagem dessas crianças, e, para isso, se propôs investigar os processos de representação, nos quais se fundam o pensamento e a linguagem. Também, no intuito de contribuir com a inclusão escolar, buscou prover aos educadores subsídios teóricos, dentro do escopo da psicanálise, que pudessem auxiliá-los na concepção de que seu aluno autista ou psicótico tem um modo singular de representar, decorrente de seus distintos processos de estruturação psíquica.

Reconhecendo a importância do aporte conceitual vindo da articulação psicanálise e educação, Fleith (2012, p. 108) acredita ser possível dizer que as crianças autistas e psicóticas têm um aparato psíquico que permite, por meio de metabolizações singulares, a associação entre as representações e a atividade do pensamento. E adota a posição de que, os educadores, uma vez conhecedores de que seus alunos autistas ou psicóticos apresentam esse modo característico de representar que os faz se anunciar, em função de suas angustias e defesas, por atitudes consideradas estranhas e diferentes, podem, por um lado, respeitar esse modo peculiar de representar, e, por outro, acolher essas angústias, apaziguando-os a ponto de eles perceberem que podem tecer uma relação outra, inserindo-se na cultura e favorecendo o pacto social. (FLEITH, 2012, p. 107-113).

A Cotarelli (2014), psicanalista, interessou fazer dos pais e responsáveis por crianças autistas ou psicóticas em processo de inclusão escolar os sujeitos da sua pesquisa, pois queria conhecer as percepções e reflexões que esses pais fazem acerca desse processo. Reconhecendo o alcance da metapsicologia, Cotarelli (2014), em seu estudo, foi buscar os conceitos de função materna e função paterna, propostos pela teoria psicanalítica, nos escritos de Lebrun (2013, p. 29), para quem a realidade psíquica do sujeito vai se organizando justamente ao encontrar a assimetria entre a função materna e a função paterna, sendo no sistema da linguagem que o Outro, exercido pela mãe desde o início, é que a criança, aspirante a sujeito, poderá sustentar seu desejo. O pai, entrando com função de alteridade, colaborará fazendo uma intervenção nessa dialética, sendo que tal operação só acontecerá se a mãe consentir ao pai esse movimento, consentimento esse que depende exatamente de ela se reconhecer como um ser faltante. 
Cotarelli, (2014, p. 100) afirma que Lebrun (2013) ressalta ser fundamental que a sociedade valorize e respeite o lugar do pai, como função de contrapeso à mãe, tanto dentro da família como no âmbito mais externo das relações sociais. No entanto, nas falas dos pais entrevistados em sua pesquisa, Cotarelli (2014) observa que "a função paterna, [...], não tem sido exercida, nem tampouco reconhecida pelo social, entendidos neste contexto pelos seus representantes: a escola, as instituições médicas e as próprias famílias”. (COTARELLI, 2014, p. 100).

A decaída do pai na era moderna já havia sido predito por Freud, segundo Kupfer (2001, p. 120), e a consequência disso é o surgimento de impasses para a constituição psíquica do sujeito na medida em que a perda de marcos organizadores provocados pela incidência da função paterna, ou Nome do Pai, como sugere o conceito lacaniano, impede que o sujeito, no início da sua constituição, se separe do outro primordial (a mãe ou função materna) e, em consequência, não se perceba um ser em falta, condição necessária para o engendramento do desejo.

O impacto da ausência desses marcos organizadores para a sociedade é a perda da relação hierárquica nos diferentes espaços sociais, que no campo da educação aparece também sob a forma de perda de autoridade dos professores, perda essa que incide tanto sobre o valor que o professor não está dando ao seu saber específico, como no recalcitrante exercício da autoridade, tomada no sentido de uma diferença hierárquica, necessária, entre a posição do professor e a do aluno. Somente ultrapassando esses impasses é que se tornará possível ao professor, por meio da linguagem, deixar marcas em seu aluno, marcas de desejo que o sujeito do inconsciente no aluno vai significar segundo o que lhe fizer sentido.

Para Kupfer (2001, p. 119), o educador que buscar a psicanálise precisa estar advertido de que angústia e modos defensivos podem emergir porque, como toda teoria, que só vai ser buscada porque algo falta, a teoria da psicanálise, o leva a se deparar com o vazio; vazio como condição para que seu desejo se apresente. Mas, paradoxalmente, somente sustentado em seu desejo é que seu ato educativo ganha significado e consistência.

Se se quer concordar que o corpo conceitual da psicanálise, ou metapsicologia, possa contribuir para o campo da educação, gerando a Articulação Psicanálise e Educação, faz-se imperativo admitir que ele adota uma

oposição à objetivação do mundo do consumo, que diz não à transformação do aluno em mercadoria, não à banalização pela inteligência emocional - banalização que nivela, acachapa, o que no sujeito é espesso, enigmático, dividido, não repetido, não em série. (KUPFER, 2001, p. 121, grifo da autora). 
E, também, é preciso considerar que, quando um professor se interessa por estudar a psicanálise e entra em contato com o conceito de sujeito, pensa estar ensinando ao sujeito do consciente quando está, de fato, pela via da transferência, falando ao sujeito do inconsciente. (KUPFER, 2001, p. 121).

Retomando aqui o terceiro objetivo do Núcleo de Estudos em Psicanálise e Educação (NEPE), resta fazer um sucinto relato das atividades de divulgação dos resultados das pesquisas, as acima expostas e as outras também realizadas. Tal divulgação se deu no Setor de Educação da Universidade Federal do Paraná, nos eventos de extensão organizados para tal fim, sendo a II Jornada de Psicanálise e Educação, realizada em setembro de 2008 , o primeiro deles. Nesse evento foi abordada a necessidade de uma interlocução da psicanálise com a educação para a discussão de uma educação inclusiva. O evento intitulado Conversando sobre Psicanálise e Educação I, ocorreu em novembro de 2009, e versou sobre a inclusão escolar de crianças e adolescentes com dificuldades em seu processo de subjetivação que apresentam necessidades educativas especiais, que foi seguido do Conversando sobre Psicanálise e Educação III, em novembro de 2011.

Os eventos seguintes foram Conversando sobre Psicanálise e Educação IV, cujo subtítulo foi Do Saber-todo ao Saber-não-todo, que aconteceu em março e abril de 2012, e, o Conversando sobre Psicanálise e Educação $V$, no qual foram apresentados os resultados das pesquisas realizadas em 2013, 2014 e 2015 e 2016, tendo como temas centrais a formação do pedagogo e do professor dos anos iniciais do ensino fundamental e a inclusão escolar de alunos autistas e psicóticos, vistas à luz da articulação psicanálise e educação.

Assim, tendo sido expostas as ações acima, verifica-se que foram atingidos os objetivos do Núcleo de Estudos em Psicanálise e Educação subsidiados pelo que no início se chamou Interlocução entre Psicanálise e Educação, e que, à medida que novas reflexões envolvendo os dois saberes iam acontecendo, resultou no termo Articulação Psicanálise e Educação. Tais reflexões foram realizadas no âmbito tanto da docência, como da pesquisa e da extensão, nesse caso nos debates nos diferentes eventos de divulgação dos resultados das pesquisas. E, assim como se depreende dessas reflexões, se evidencia a importância da articulação psicanálise e educação para que professores e educadores de modo geral conheçam os conceitos da metapsicologia, se permitindo construir com eles uma nova concepção de educação e consequentes inovações em seu ato educativo.

Expostos os trabalhos do NEPE nos âmbitos da docência, da pesquisa e da extensão, dentro de uma conformação universitária, parece convir fazer aqui algumas considerações. A primeira delas se dirige ao escopo propriamente conceitual, no sentido de que quando se traz a psicanálise para o campo da educação sempre é preciso estar advertido de que é certo que a cada passo, claudicante, 
se está frente ao vazio, àquilo de que não se sabe ao certo - condição para a emergência do desejo, como vimos.

Falar de falta, vazio, brechas, sujeito cindido, Mestre-não-todo dentro de um curso de Pedagogia, que se estrutura de um modo geral, dentro e fora do escopo da Psicologia da Educação, no campo da certeza ditada pela (psico) pedagogia, equívoco apontado por Lajonquière (1999; 2009), mostrou-se um desafio ao longo de todos esses anos. Um desafio compartilhado com cada aluna que se dedicou com afinco e espanto a esmiuçar cada conceito, a buscar os nexos entre os significados, a garimpar a coerência interna nos escritos dos autores, seja durante as aulas, seja nas pesquisas - de mestrado (abordadas neste trabalho), de iniciação científica, ou em trabalho de conclusão de curso - seja nos invariáveis debates nos eventos de extensão.

Esse é um desafio que, no entanto, não se encerra em si. Outros desdobramentos surgem demarcando a necessidade de se falar de outros limites e alcances acerca da contribuição que a Articulação Psicanálise e Educação possa trazer ao educador. Uma delas está apreendida na pergunta que Almeida (2006) faz a partir da posição de Freud (1925/1976b, apud ALMEIDA, 2006): "Podemos nos perguntar, então, para finalizar, mas não para concluir: seria a demanda de análise um dos destinos privilegiados da relação transferencial na transmissão da psicanálise a educadores?”. (ALMEIDA, 2006, p. 22, grifos da autora).

Diante da demanda de alunas e alunos que se colocam na posição de adotar o referencial elaborado pela Articulação Psicanálise e Educação em seus estudos, Kupfer (2001) admite "que não podemos nos furtar à responsabilidade que temos diante desse fenômeno; nossa responsabilidade advém da transferência de que somos alvo e que vem dos educadores". (KUPFER, 2001, p. 120). Mas aí, dentre várias, uma questão se coloca: se, por um lado, a psicanálise é constituída pela tríade tratamento, método de investigação e conjunto teórico, ou metapsicologia, e que muitos preconizam que a análise pessoal do professor, educador, pesquisador seria "um autorizar-se que é, sobretudo, ético, porque o ideal educativo irá esbarrar, sempre, em algo da pulsão que é indomável, ineducável (ALMEIDA, 2003 , p. 21), e, por outro, conhecidas as condições, notadamente, mas não exclusivamente, as econômicas, como condicionar os estudos desses alunos, movidos pelo desejo de saber, à exigência de uma análise pessoal?

O que sugerir para que o professor, educador, pesquisador, movido por seu desejo de saber da psicanálise, não desista de caminhar nessa senda tão profícua constituída pela Articulação Psicanálise e Educação, tão bem ilustrada pelos trabalhos de pesquisa de mestrado realizados por alunas-professoras e alunas-psicanalistas, vinculadas ao Núcleo de Estudos em Psicanálise e Educação, apresentados neste breve artigo? 


\section{REFERÊNCIAS}

ALMEIDA, S. F. C. Transmissão da psicanálise a Educadores: do ideal pedagógico ao real da (trans)missão educativa. Estilos da Clínica, São Paulo, v. XI, n. 21, p. 14-23, 2006.

COTARELLI, C. M. A inclusão escolar de alunos autistas e psicóticos: a percepção dos pais. 115 p. Dissertação (Mestrado em Educação) - Setor de Educação, Universidade Federal do Paraná, Curitiba, 2014.

FERNANDES, C. A. V. A relação do professor com seu aluno psicótico em processo de inclusão escolar: a palavra e o ato. Dissertação (Mestrado em Educação) - Setor de Educação, Universidade Federal do Paraná, Curitiba, 2013.

FERREIRA, A. B. H. Novo Dicionário da Língua Portuguesa. 1. ed. 5. reimp. Rio de Janeiro: Nova Fronteira, 1975.

FLEITH, V. Aspectos concernentes às origens do psiquismo na estruturação das crianças autistas e psicóticas: contribuições ao contexto da educação inclusiva. 119 p. Dissertação (Mestrado em Educação) - Setor de Educação, Universidade Federal do Paraná, Curitiba, 2012.

GARCIA-ROZA, L. A. Introdução à metapsicologia freudiana. v. 1: sobre as afasias, (1891): o projeto de 1895. 7. ed. Rio de Janeiro: Jorge Zahar, 2008.

KUPFER, M. C. Uma educação para o sujeito do livro Educação para o futuro: psicanálise e educação. 2. ed. São Paulo: Escuta, 2001.

LAJONQUIÈRE. L. de. Educação e Infanticídio. Educação e revista, Belo Horizonte, v. 25, n. 01, p. 165-177, abr. 2009. Disponível em: <http://www.scielo.br/pdf/edur/v25n1/09. pdf>. Acesso em: 06 maio 2015.

LAJONQUIĖRE, L. de. Infância e ilusão (psico)pedagógica: escritos de psicanálise e educação. 4. ed. Petrópolis: Vozes, 2009.

LAPLANCHE, J.; PONTALIS, J. B. Vocabulário da psicanálise. 7. ed. São Paulo: Martins Fontes, 1983.

LOPES, L. C. C. A articulação psicanálise e educação e o aluno-sujeito. 77 p. Dissertação (Mestrado em Educação) - Setor de Educação, Universidade Federal do Paraná, Curitiba, 2014.

PUCOVSKI, K. P. G. F. Aspectos da inclusão escolar da criança autista: o aluno-sujeito. 105 p. Dissertação (Mestrado em Educação) - Setor de Educação, Universidade Federal do Paraná, Curitiba, 2013.

ROUDINESCO, E.; PLON, M. Dicionário de psicanálise. Rio de Janeiro: Zahar, 1988.

SALGADO, A. M. Impasses e passos na inclusão escolar de crianças autistas e psicóticas: o trabalho do professor e o olhar para o sujeito. 139 p. Dissertação (Mestrado em Educação) - Setor de Educação, Universidade Federal do Paraná, Curitiba, 2012. 
STRACHEY, A. Edição Standard Brasileira das obras Psicológicas Completas de Sigmund Freud. Rio de Janeiro: Imago, 1977. v. I. (Original publicado em 1969.)

TOREZAN, Z. C. F.; AGUIAR, F. O sujeito da psicanálise: particularidades na contemporaneidade. Revista Mal-estar e Subjetividade, Fortaleza, v. XI, n. 2, p. 525-554, jun./2011.

VALENTE, T. S. Proposta de criação do Núcleo de Estudos em Psicanálise e Educação do Setor de Educação da Universidade Federal do Paraná - NEPE. Setor de Educação. Universidade Federal do Paraná. Curitiba, 2008. Não publicado.

VIEIRA, F. M. A caracterização do sujeito freudiano a partir do conceito de trieb. Revista AdVerbum, v. 5, n. 2, p. 90-97, Ago./Dez. 2010.

Texto recebido em 17 de dezembro de 2016.

Texto aprovado em 03 de janeiro de 2017. 